\title{
El precedente del Consejo de Estado en las fuentes del derecho administrativo*
}

\author{
Recibido: 10 de marzo de 2017 • Aprobado: 16 de febrero de 2018 \\ https://doi.org/10.22395/ojum.v18n36a1 1
}

Kennier José Garay Herazo**

\begin{abstract}
RESUMEN
Este artículo se ocupa de reflexionar sobre el papel del precedente judicial del Consejo de Estado con respecto al sistema de fuentes del derecho administrativo colombiano. Por tanto, su propósito principal es aportar elementos de análisis que contribuyan al esclarecimiento de su rol como fuente principal. Para ello, se parte de contextualizar, definir y diferenciar nociones como las de jurisprudencia y precedente. Luego, se revisa la evolución de estos conceptos en la Corte Constitucional y en la Corte Suprema de Justicia, para evaluar su uso en las decisiones del Consejo de Estado. Con relación a este último, se enfatiza en las sentencias de unificación jurisprudencial, las cuales poseen una fuerza vinculante de rango legal. No obstante, por razones sistemáticas se sostiene que en esta "jurisdicción", no solo ellas configuran precedente judicial.

Palabras clave: precedente; Consejo de Estado; jurisprudencia; fuentes; sentencias de unificación; ratio decidendi.
\end{abstract}

\footnotetext{
Artículo de reflexión. Este texto surge como resultado del trabajo autónomo de su autor, en el marco del proyecto de trabajo de grado desarrollado para optar al título de especialista en Derecho Administrativo de la Universidad de Antioquia, Medellín, Colombia.

** Abogado, Universidad de Antioquia, Medellín, Colombia, politólogo, Universidad Nacional de Colombia Medellín, especialista en Derecho Administrativo, Universidad de Antioquia, Medellín, Colombia Profesor e investigador del grupo de investigación Derecho, Cultura y Ciudad de la Universidad de San Buenaventura Medellín, Colombia. Profesor de cátedra, Universidad de Antioquia, Medellín, Colombia. Correo electrónico: kennier.garay@usbmed.edu.co - kennier.garay@udea.edu.co. Orcid: https://orcid. org/0000-0001-5437-4380.
} 


\section{The precedent of the Council of State in the sources of administrative law}

\section{ABSTRACT}

This article deals with reflecting on the role of the judicial precedent of the Council of State in relation to the system of sources of Colombian administrative law. Therefore, its main purpose is to provide elements of analysis that contribute to elucidating its role as the main source. To do this, we start by contextualizing, defining and differentiating notions such as jurisprudence and precedent. Then, the evolution of these concepts in the Constitutional Court and the Supreme Court of Justice is reviewed in order to evaluate its use in the Council of State's decisions. Regarding the latter, particular attention is given to the judgements of jurisprudential unification, which have a binding force of legal status. However, for systematic reasons it is argued that, in this "jurisdiction", they are not the only ones that set a judicial precedent.

Keywords: precedent; Council of State; jurisprudence; sources; unification sentences; ratio decidendi.

\section{0 precedente do Conselho de Estado nas fontes do direito administrativo}

\section{RESUMO}

Este artigo se ocupa de refletir sobre o papel do precedente judicial do Conselho de Estado com respeito ao sistema de fontes do direito administrativo colombiano. Portanto, seu propósito principal é oferecer elementos de análise que contribuam para o esclarecimento de seu papel como fonte principal. Para isso, parte-se de contextualizar, definir e diferenciar noções como as de jurisprudência e precedente. Em seguida, revisa-se a evolução desses conceitos na Corte Constitucional e na Corte Suprema de Justiça para avaliar seu uso nas decisões do Conselho de Estado. Com respeito a este último, enfatiza-se nas sentenças de unificação jurisprudencial, as quais têm uma força vinculante de alcance legal. Não obstante, por razões sistemáticas, defende-se que nessa "jurisdição" não são apenas elas que configuram precedente judicial.

Palavras-chave: precedente; Conselho de Estado; jurisprudência; fontes; sentencias de unificação; ratio decidendi. 


\section{INTRODUCCIÓN}

El objetivo principal de este artículo consiste en aportar elementos teórico-prácticos de análisis, que contribuyan al esclarecimiento del papel y uso del precedente judicial en el marco del sistema de fuentes del derecho para el juez contencioso administrativo en Colombia. Propósito oportuno si se considera que la conjugación de elementos históricos, normativos, culturales y teóricos han incidido en la configuración del actual esquema de fuentes del derecho colombiano, el cual resulta complejo y problemático frente a algunos asuntos como los relativos a la fuerza vinculante, tipos y nivel de obligatoriedad del precedente judicial.

En perspectiva histórica, es importante tener en cuenta que durante las últimas décadas han sido frecuentes los denominados choques de trenes en los escenarios judiciales colombianos. Las situaciones de 'choque' no han sido otra cosa distinta a la expedición de providencias judiciales por parte de cortes o distintas salas, secciones o subsecciones que se pronuncian de forma divergente sobre un mismo supuesto, lo que genera decisiones favorables en unos casos y desfavorables en otros, frente a una misma situación de derecho.

El escenario descrito no ha sido pacífico y ha generado opiniones encontradas. De un lado, se percibe con escepticismo la situación, en tanto se asume como lesiva de la seguridad jurídica y la certeza judicial. Mientras que, de otro lado, es valorada de forma positiva en la medida en que se considera que estos choques propician la imparcialidad e independencia judicial como garantía de los derechos sometidos a la solución dada por un tercero imparcial.

Sin embargo, la dificultad puede apreciarse frente a los jueces de inferior jerarquía, abogados litigantes y asesores, quienes en su quehacer profesional se enfrentan a casos para los que es posible apreciar la divergencia comentada, puesto que, se suelen encontrar, como mínimo, con dos posiciones jurisprudenciales que, prima facie, resultan aplicables a su supuesto o, por lo menos, pueden ser premisas judiciales factibles. En otros términos, encuentran razones válidas para la construcción de su argumentación frente al caso.

La situación descrita da lugar a la siguiente pregunta: ¿cuál de las dos tesis jurisprudenciales debe aplicar el juez que resuelve un caso análogo? Interrogante que permite advertir que el tema transversal -y de mayor importancia- es el referido al sistema de fuentes del derecho y, de forma especial, al papel que ostentan la jurisprudencia y el precedente judicial como fuentes de derecho a tener en cuenta por parte del juez. 
Para lograr el objetivo planteado en este artículo de reflexión, se parte de un enfoque cualitativo, que se desarrolla a partir de la identificación y descripción de aspectos teóricos generales. Luego se despliega un análisis que permite conceptualizar la vinculatoriedad de las manifestaciones judiciales de las principales altas cortes colombianas. Ejercicio realizado en dos niveles, uno descriptivo y de agrupación de categorías, y uno analítico o reflexivo a partir del primero. Se emplea, por tanto, una metodología de análisis conceptual que revisa doctrina especializada y jurisprudencia colombiana de la Corte Constitucional, la Corte Suprema de Justicia y el Consejo de Estado, puesto que la fundamentación conceptual en materia de precedente judicial es común a estas 'jurisdicciones'.

En suma, el corpus de este artículo se compone de tres grandes capítulos temáticos y un acápite final de conclusiones. En el primer capítulo se realiza una presentación conceptual e histórica del sistema de fuentes del derecho, así como las dificultades asociadas al tratamiento indistinto que se ha dado al precedente judicial y a la jurisprudencia en Colombia. En el segundo capítulo se lleva a cabo una revisión panorámica a la evolución sobre la noción del precedente judicial frente a las decisiones de la Corte Constitucional y la Corte Suprema de Justicia. El tercer capítulo se ocupa de presentar la revisión al precedente judicial en las decisiones del Consejo de Estado y su función como fuente principal para el juez contencioso administrativo. Este ejercicio se lleva a cabo en dos momentos: uno previo a la expedición del Código de Procedimiento Administrativo y Contencioso Administrativo (Cpaca) y uno posterior a esta. Por último, en el cuarto capítulo se presenta un breve balance de conclusiones.

\section{EL SISTEMA DE FUENTES DEL DERECHO PARA EL JUEZ EN COLOMBIA: EL PRECEDENTE Y LA JURISPRUDENCIA}

\subsection{Contexto histórico y fuentes del derecho en Colombia}

El concepto de fuentes del derecho se considera como un asunto elemental, al cual se le suele prestar poca atención, tanto en el plano académico como práctico del derecho. Sin embargo, cuando se trata de precisar el alcance del término y así determinar qué implica o a qué está referido, surgen diferentes significaciones que complejizan su uso, y por tanto, resignifican sus consecuencias teórico-prácticas. En este sentido, Aguiló (2015) plantea un inventario que contiene por lo menos tres grandes caminos para definir las fuentes: i) el explicativo o social, ii) el justificativo o valorativo y iii) el sistemático o formalista.

El primero de estos sentidos asume las fuentes como el conjunto de causas sociales que dan origen a los fenómenos jurídicos, en tanto son -a su vez- fenómenos 
sociales. El segundo, por el contrario, se encarga de entender a las fuentes como la fundamentación de la obligatoriedad del derecho, es decir, responde a la pregunta de ¿̇por qué el derecho obliga?l Para el tercero y último, las fuentes son el origen de los fenómenos jurídicos en tanto se asumen como hechos autónomos, puesto que el derecho es un orden normativo que se autorregula, en la medida en que contiene normas jurídicas que determinan la producción de otras normas de la misma índole (Aguiló, 2015).

Dada su vocación regulativa, el tercero de los sentidos que han sido referidos será el acogido en este texto. Ahora bien, este implica tres subcampos de significación que grosso modo dan cuenta de, en primer lugar, la potestad de creación normativa de titularidad de las "autoridades y particulares. En el segundo, fuente como norma de segundo grado para la producción de nuevas normas o fuente como el derecho objetivo mismo. En el tercero, fuente como origen del conocimiento jurídico" (Cárdenas, 2009, p. 157).

Sin entrar en los pormenores de los desarrollos que a la luz de la teoría del derecho puedan hacerse sobre los matices en estos tres subsentidos, para el contexto del derecho administrativo colombiano, en este texto se alude a fuentes del derecho en el segundo subsentido. Es decir, como las normas de segundo nivel que con relación a otras determinan las razones, procedimientos, competencias o contenidos para la creación de otras normas. Entendidas de esta forma, se tiene que la Constitución, las leyes, los tratados internacionales ratificados por el Estado, los actos administrativos, los reglamentos, las sentencias, los contratos, la doctrina, los principios generales del derecho, entre otros, constituyen fuentes del derecho.

En Colombia las fuentes del derecho no han sido estáticas, han mutado de la mano de los principales cambios institucionales y normativos del ordenamiento jurídico durante toda su historia republicana. De hecho, el último cambio significativo en el sistema de fuentes ocurrió a partir de la promulgación de la Constitución Política de 1991. Con su entrada en vigencia, este se dinamizó a partir de las decisiones de las altas cortes, lo que implicó un constante reposicionamiento en lo que respecta a su vinculatoriedad.

Si se revisa el texto constitucional se aprecia que el constituyente definió las fuentes del derecho para las autoridades jurisdiccionales, en: i) principales y ii) auxiliares. En otros términos, cualquier juez colombiano debe proferir sus fallos de acuerdo con la competencia, procedimientos y directrices materiales que se encuentran en las distintas fuentes del derecho. Sin embargo, para esto debe atender a las denominadas

Sentido que en la teoría del derecho parece estar más próximo a las reflexiones sobre la denominada normatividad del derecho. 
fuentes principales y a falta de estas o a manera de complementación: acudir a las fuentes auxiliares.

Aunque la literalidad de la disposición constitucional en comento parece ser clara, en los últimos años se han generado múltiples dificultades en cuanto al uso de la jurisprudencia y el precedente judicial como fuentes del derecho, pues su carácter principal o auxiliar ha sido objeto de variadas discusiones.Ya que, de un lado, el constituyente se refirió a la jurisprudencia como criterio auxiliar y, de otro lado, el devenir judicial ha catalogado al precedente como fuente principal. Situación que ha permeado las distintas áreas del derecho colombiano, incluido, por supuesto, el derecho administrativo.

Teniendo en cuenta ese núcleo compartido, a continuación se realiza una conceptualización particular en torno a las nociones de precedente judicial y jurisprudencia como fuentes del derecho en Colombia.

\subsection{El precedente judicial y la jurisprudencia como fuentes de derecho en Colombia}

En el país se han generado discusiones sobre el papel del precedente judicial y la jurisprudencia, en términos de su rol como fuentes (principales o auxiliares) de derecho. En primer lugar, vale la pena mencionar que sus orígenes jurídico-institucionales se encuentran próximos a las tradiciones jurídicas agrupadas bajo el rótulo de romanogermánicas o también denominadas de civil law. Estas se han caracterizado por un sistema de fuentes en el que cobró especial importancia la ley como fuente principal, lo que ha relegado la jurisprudencia a un segundo plano. Estados europeos como España, Francia y Alemania, compartieron elementos comunes a dichas tradiciones, que fueron legados a sus diferentes colonias (Díez, 2008).

En oposición a las anteriores tradiciones se encuentran las de corte angloamericanas o sistemas del common law, en las que las manifestaciones judiciales han sido catalogadas como fuente principal y su obligatoriedad, por regla general, no se pone en entredicho. Tradiciones más arraigadas entre los países que tuvieron una vinculación colonial inglesa (García, 2004).

No es posible hacer una separación tajante que permita catalogar el sistema jurídico de un Estado como un sistema de tradición pura, por tanto, de fuentes de una u otra familia. En consonancia con esta precisión, para el caso de Colombia existe una proximidad historicocultural hacia las familias del civil law. No obstante, a partir de la Constitución de 1991, a pesar de tener una fuerte vocación legalista, ha incorporado, vía actuaciones jurisprudenciales y a través de la doctrina, elementos propios del common law, como sucede con el referido a la institución del precedente judicial. 
Si se revisa la Constitución Política de 1991, se advierte que ninguno de sus artículos se refiere de forma expresa al precedente judicial. De hecho, al examinar la literalidad del artículo 230, que consagra el esquema de fuentes de derecho dentro del texto constitucional, este establece que: "los jueces, en sus providencias, sólo están sometidos al imperio de la ley. (...) La equidad, la jurisprudencia, los principios generales del derecho y la doctrina son criterios auxiliares de la actividad judicial".

Como se desprende de la lectura literal del texto en comento, este solo se refiere a la jurisprudencia, no al precedente, expresión que en sus alcances: semántico y jurídico es diferente de la simple jurisprudencia, en cuanto a su rol de fuente de derecho vinculante. Habiendo aquí otra causa, pero ya no de tipo histórico o cultural, sino conceptual, al tratar de forma indistinta las expresiones: jurisprudencia y precedente. Aunque tal tratamiento no solo sucede en los textos normativos², en el lenguaje corriente los significados no suelen ser diferenciados, aun cuando sí existen diferencias sustanciales entre ambos (Taruffo, 2007).

El rol del precedente a manera fuente vinculante en Colombia ha sido dado por vía jurisprudencial, como ejemplo de ello se encuentra, entre otras, lo planteado en la Sentencia C-836 de 2001. Sin embargo, en la actualidad se presentan algunas variaciones sobre su vinculatoriedad de acuerdo con la respectiva área jurisdiccional y el tipo de sentencia que se analice. En este sentido, amerita especial mención, la 'jurisdicción' contenciosa administrativa, ya que cuenta, a diferencia de las otras, con una explícita regulación legal frente al tema jurisprudencial.

\section{PANORÁMICA AL PRECEDENTE JUDICIAL EN LAS DECISIONES DE LA CORTE CONSTITUCIONAL Y LA CORTE SUPREMA DE JUSTICIA}

En tanto se parte de la existencia de elementos comunes en las distintas áreas jurisdiccionales en Colombia, necesarios para una mejor conceptualización del precedente judicial en el esquema de fuentes en el derecho administrativo, a continuación se presenta un desarrollo sucinto del mismo frente a la Corte Constitucional y a la Corte Suprema de Justicia.

\subsection{Evolución de la noción de precedente frente a las decisiones de la Corte Constitucional}

La Corte Constitucional ha jugado un papel clave en el sistema judicial colombiano durante las últimas dos décadas. Sus decisiones han sido indispensables para desarrollar la comprensión, efectos e implicaciones del precedente judicial dentro

2 Un claro ejemplo de esta situación es el referido en el contenido del Auto 223 de la Corte Constitucional (2006a). En este se plantea de forma explícita los usos imprecisos que en ocasiones ha realizado la misma corporación. 
del sistema de fuentes del derecho colombiano. Así, para entender este rol, resulta indispensable responder los dos siguientes interrogantes: i) ¿Cuáles de sus decisiones son vinculantes? y ii) ¿Qué parte de estas es vinculante?

Para responder estos interrogantes, se alude, de un lado, al control de constitucionalidad en abstracto que realiza la Corte sobre los actos reformatorios de la Constitución, las leyes y demás normas con fuerza material de ley (sentencias de nomenclatura C). Mientras que, de otro lado, se analizan los mismos interrogantes en instancia de control concreto de constitucionalidad (sentencias de nomenclaturas T y SU).

Con respecto al interrogante de la vinculatoriedad, para el caso de las sentencias C, el artículo 243 constitucional establece que dichas decisiones hacen tránsito a cosa juzgada constitucional. Por tanto, si la Corte declara la inexequibilidad de las disposiciones acusadas, ninguna autoridad podrá reproducirla en una nueva normativa, siempre y cuando se preserven las razones constitucionales de dicha declaratoria. Sumado a ello, el artículo 21 del Decreto 2067 de 1991, reafirmó la voluntad del constituyente al establecer que "las sentencias que profiera la Corte Constitucional tendrán el valor de cosa juzgada constitucional y son de obligatorio cumplimiento para todas las autoridades y los particulares".

El inciso primero del artículo 23 del aludido decreto estableció que "la doctrina constitucional enunciada en las sentencias de la Corte Constitucional, mientras no sea modificada por ésta, será criterio auxiliar obligatorio para las autoridades y corrige la jurisprudencia". Regulación que denotó poca precisión conceptual del ejecutivo frente a la jurisprudencia constitucional y los tipos de fuentes, de forma que la expresión: 'obligatorio', tuvo que ser declarada inexequible por la Corte Constitucional mediante la Sentencia C-131 de 1993. En dicha decisión, el alto tribunal precisó que no todo el contenido de estas sentencias tiene carácter de cosa juzgada, de lo que se deriva que no todos los elementos que la conforman son obligatorios (Corte Constitucional, 1993).

Razonamiento que debe tomarse con cautela, ya que en él la Corte asoció indistintamente la institución jurídica de la cosa juzgada con la caracterización de la obligatoriedad del precedente judicial. Aceptando los reparos al mismo, en el supuesto donde coincidan cosa juzgada y obligatoriedad, surge el siguiente interrogante: ¿̇cuáles son los elementos de la sentencia que hacen tránsito a cosa juzgada, ergo, se entenderán como obligatorios?

Para responder a este interrogante, la sentencia en comento precisa que el carácter de cosa juzgada se refleja de dos maneras, tanto de forma i) explícita como ii) implícita. La primera, tratándose de la parte resolutiva de la decisión, y la segunda en cuanto a los apartados de la parte motiva que son imprescindibles para darle sentido y unidad 
a la parte resolutiva. En otras palabras, aquellos argumentos sin los cuales carece de sentido lo resuelto en la decisión judicial (Corte Constitucional,1993).

En relación con los elementos vinculantes implícitos en la parte motiva de la decisión judicial, la Corte reiteró que no es toda, sino solo una parte de la misma, que debe hallarse teniendo en cuenta que la mayoría de estos componentes tienen connotación de auxiliares, es decir, de obiter dicta. Sin embargo, no puede afirmarse lo mismo de los fundamentos que guardan relación directa con la parte resolutiva de la decisión de constitucionalidad, o aquellos que la Corte indique -de forma explícitaque deben ser obligatorios y, en consecuencia, modificatorios de jurisprudencia, si a ello hubiere lugar (Corte Constitucional, 1993).

En 1996 fue expedida la Ley 270, ley estatutaria de administración de justicia. Su artículo 48 se ocupó de precisar el alcance de los efectos de las sentencias de la Corte Constitucional. El numeral primero de este artículo estableció que las sentencias de constitucionalidad solo serían de "obligatorio cumplimiento y con efecto erga omnes en su parte resolutiva. La parte motiva constituirá criterio auxiliar para la actividad judicial y para la aplicación de las normas de derecho en general". No obstante, al tratarse una ley de naturaleza estatutaria, fue objeto del control de constitucionalidad previo y automático, que, través de la Sentencia C-037 de 1996, moduló su contenido al condicionar la interpretación del artículo citado. Decisión con la que asumió de forma tímida lo que, de manera previa, había planteado en la Sentencia C-131 de 1996.

Según lo preceptuado por la Corte, en primer lugar, ostentaría la calidad de obligatorio lo contenido en la parte resolutiva de sus sentencias. En consecuencia, señaló como criterios auxiliares para la actividad judicial y la aplicación de las normas del derecho en general: aquellos contenidos de la parte motiva que no lograsen entablar relación directa y necesaria con lo resuelto. Por tanto, se deduce entonces que sí serían vinculantes aquellos conceptos o fundamentos que conformaran la argumentación "básica, necesaria e indispensable para servir de soporte directo a la parte resolutiva de las sentencias y que incida directamente en ella" (Corte Constitucional, 1996).

A diferencia de las sentencias de constitucionalidad, en su parte resolutiva, las sentencias de revisión de tutela -en principio- solo tienen carácter obligatorio para las partes del respectivo proceso. Sin embargo, tratándose de su parte motiva, el inciso segundo del artículo 48 de la Ley 270 de 1996, estableció que "su motivación sólo constituye criterio auxiliar para la actividad de los jueces". Prescripción cuya constitucionalidad -como ya se dijo-fue condicionada por la Sentencia C-037 de 1996, de forma que una parte de este tipo de decisiones sí es vinculante. Pero ¿qué parte de la decisión puede ser vinculante para otros casos? ¿A qué tipos de casos debe aplicarse? 
Con relación a los interrogantes planteados, en la Sentencia T-260 de 1995 la Corte (1995a) emplea la expresión doctrina constitucional para referirse a todos aquellos criterios judiciales derivados de la aplicación de las disposiciones y normas constitucionales que, a su juicio, se tornan indispensables para precisar el alcance de los derechos fundamentales.

Para reforzar la obligatoriedad de dichos criterios, la Corte sostuvo que, aunque la jurisprudencia no era obligatoria (inciso segundo del artículo 230), las pautas y directrices que emite en ejercicio de la guarda de la supremacía e integridad del texto constitucional señalan a todos los jueces el alcance y sentido de la normativa fundamental a la cual deben sujetarse. En caso de contrariarla o ignorarla, estarían incurriendo en la violación de la Constitución y no solo distanciándose de cualquier jurisprudencia, como podría acontecer frente a la penal, civil, laboral o contenciosa administrativa (Corte Constitucional, 1995a).

Aunque en la sentencia precitada la Corte solo se refirió a la doctrina constitucional y no al precedente, en ella se encuentran los principales fundamentos que soportan el precedente judicial constitucional en materia de revisión de tutelas. Lo que luego sería reafirmado en la Sentencia T-175 de 1997, en la que sí aludió de forma expresa al precedente. En esta decisión planteó que -incluso- ella misma como corporación, estaba obligada a acatar el sentido y las consecuencias jurídicas que se derivan de los precedentes judiciales formulados por sus salas de revisión de tutela, con los que se ha formado doctrina constitucional. Así las cosas, cuando se tratase de un cambio de directriz constitucional, esta decisión tendría que ser tomada de forma exclusiva por la Sala Plena. En consecuencia, sostuvo que, si así ocurría para el máximo tribunal constitucional, no sería justificable que jueces de inferior jerarquía dentro de la misma jurisdicción (esto es, todos los jueces en tanto sean constitucionales), se apartaran de su doctrina constitucional sin tener argumentos sólidos para ello (Corte Constitucional, 1995b).

Además de los argumentos ya esbozados en favor de la fuerza vinculante del precedente en sede de revisión de tutela, en la sentencia comentada, la Corte dejó claro que su fundamento era la garantía del derecho fundamental de igualdad ante la administración de justicia, puesto que no sería justificado dar tratamiento diferenciado a personas que se hallen inmersas en los mismos supuestos fácticos y normativos. Criterio que se debe respetar cuando se vayan a resolver casos análogos a otros ya revisados por la Corte, "lo que confiere especial valor al precedente" (Corte Constitucional, 1995b). En otros términos, la exigibilidad del precedente judicial se predica ante casos similares, pues no tiene sentido aplicar las mismas soluciones judiciales de casos configurativos de supuestos disímiles. 
Si se asume que el precedente es el componente vinculante de la decisión judicial para casos análogos, es decir, aquellos aspectos que no se agotan en el simple decisum, entonces el precedente judicial será lo mismo que la ratio decidendi. Componente que también ha sido objeto de diversas controversias de tipo conceptual frente a su definición. Al respecto pueden hallarse, por lo menos, tres sentidos para definir lo que significa la ratio decidendi. El primero está referido a la norma jurídica general con base en la que se resuelve un caso. El segundo alude a la norma jurídica contextualizada en la descripción y los argumentos que soportan la decisión del caso. El tercero y último, la define como cualquier aspecto esencial de la argumentación que construye el juez para motivar su decisión en el caso sub judice (Igartúa, 2006).

Frente a la noción de ratio decidendi, en un primer momento, la Corte planteó que consistía en la "formulación general, más allá de las particularidades irrelevantes del caso, del principio, regla o razón general que constituyen la base de la decisión judicial específica" (Corte Constitucional, 1999). Sin embargo, aunque esta definición fue dominante durante algunos años, las dificultades prácticas derivadas de su vaguedad, condujeron a modificaciones sustanciales con el paso del tiempo.

Variaciones que dan cuenta de la toma de postura en favor del segundo sentido de ratio decidendi y, por tanto, del precedente, expuestos en este texto. Así puede apreciarse en la Sentencia C-836 de 2001, en la que refiriéndose a la ratio decidendi, indicó que la vinculación formal para el juez no está referida a un fragmento descontextualizado de los hechos y la decisión, de ahí la importancia que las altas cortes procuren su planteamiento explícito para su adecuación ante cada caso concreto (Corte Constitucional, 2001). La importancia de esta segunda noción estriba en el hecho de que implica la contextualización del caso, es decir, resulta más funcional.

A manera de síntesis, se tiene que, si bien es cierto que la jurisprudencia es la manifestación por excelencia de la actividad judicial, por regla general, su vinculatoriedad como fuente principal está dada por la figura de la ratio decidendi, que es el componente de la decisión judicial que configura el precedente. Así las cosas, en aras de la protección del derecho a la igualdad, la seguridad y la certeza jurídica, un caso pendiente de resolución debe ser fallado conforme a casos anteriores, siempre y cuando: i) exista similitud o semejanza en los supuestos de hecho relevantes de ambos casos, ii) la consecuencia jurídica aplicada para el caso anterior encaje con la pretensión del caso pendiente, y iii) no haya ocurrido variación en la regla jurisprudencial que la haga distinta o modifique los supuestos de hecho exigidos para su aplicación (Corte Constitucional, 2006b).

Para cerrar este apartado, es prudente insistir en que la identificación de la ratio decidendi y, en consecuencia, del precedente, no siempre suele ser una labor sencilla. 
Así como tampoco la calificación del resto de elementos de la decisión; es decir, los obiter dicta, que serían los demás argumentos y enunciados que no se comportan como elementos indispensables o necesarios para sustentar la decisión (Corte Constitucional, 2001). En consecuencia, la labor interpretativa y argumentativa de catalogarlos de una u de otra forma, hará que se postulen como fuente principal vinculante o, en su defecto, como afirmaciones jurisprudenciales que constituyen criterio auxiliar de la actividad judicial.

\subsection{Evolución de la noción de precedente frente a las decisiones de la Corte Suprema de Justicia}

La Corte Suprema de Justicia es el alto tribunal con mayor antigüedad en Colombia. Un rastreo a su historia permite apreciar que a pesar de la influencia que ha tenido el derecho continental sobre el ordenamiento colombiano, esta se hizo merecedora de reconocimiento en su labor, al proferir varias sentencias en las que incorporó nuevos elementos jurídicos que no contaban con enunciación legal, en la medida en que provenían de desarrollos judiciales de jurisprudencia extranjera.

Aunque las mencionadas incorporaciones no alcanzaron el estatus legislativo, fueron empleadas por los jueces civiles para argumentar y resolver casos análogos, práctica que ha configurado - una especie de-reglas jurisprudenciales que, con el paso del tiempo, serían consolidadas a través de sus decisiones de casación, figura que le permitió unificar su jurisprudencia a lo largo de los años (Bernal, 2008).

La Corte Suprema de Justicia ha desarrollado sus tesis jurisprudenciales en el contexto de la denominada doctrina probable. La doctrina probable, también es denominada jurisprudencia constante o doctrina legal en Estados como Francia y España. Figura que es propia de sistemas de civil law o legalistas, que tienden a considerar la jurisprudencia como fuente auxiliar, entendiendo que ella no genera obligaciones generales, sino que es un asunto de interpretación del juez para la aplicación de la ley y que, por tanto, cuenta con relativo grado de autoridad dentro de la estructura judicial (Corte Constitucional, 2015).

La figura de la doctrina probable fue regulada por el artículo 4 de la Ley 169 de 1896, según el cual:

Tres decisiones uniformes dadas por la Corte Suprema como Tribunal de Casación sobre un mismo punto de derecho, constituyen doctrina probable, y los Jueces podrán aplicarla en casos análogos, lo cual no obsta para que la Corte varíe la doctrina en caso de que juzgue erróneas las decisiones anteriores.

La aplicación de la Ley 169 hizo carrera en la jurisdicción ordinaria y funcionó sin mayores reparos durante más de un siglo, no obstante, luego del cambio nor- 
mativo que se produjo en el ordenamiento jurídico colombiano a partir de 1991, surgieron dificultades prácticas por la intercepción de las decisiones de los distintos órganos judiciales. De forma particular, la introducción activa que fue llevada a cabo por la Corte Constitucional frente al tema del precedente y su fuerza vinculante, ocasionada, en parte, por la posibilidad y empleo de acciones de tutelas contra providencias judiciales.

A partir del contexto descrito, la Corte Constitucional se pronunció en la Sentencia C-836 de 2001, que declaró la exequibilidad condicionada de la disposición que consagra la doctrina probable. Condicionamiento que se hizo en el sentido de establecer que la Corte Suprema de Justicia, como juez de casación, y los demás jueces que conforman la jurisdicción ordinaria, tienen la obligación de exponer, de forma clara y razonada los argumentos jurídicos por los cuales optan por separarse de la doctrina probable.

La modulación interpretativa que estableció la Corte Constitucional a la doctrina probable, luego sería incorporada al rango legal en el inciso segundo del artículo $7^{\circ}$ del Código General del Proceso (Ley 1564 de 2012), según el cual, "cuando el juez se aparte de la doctrina probable, estará obligado a exponer clara y razonadamente los fundamentos jurídicos que justifican su decisión. De la misma manera procederá cuando cambie de criterio en relación con sus decisiones en casos análogos".

La obligación que la Corte Constitucional había establecido frente a la doctrina probable, luego se extendió por vía legal a los supuestos en los que el juez pretende variar de posición frente a casos análogos en los que ya se haya pronunciado de forma previa. Es decir, en eventos en los que, stricto sensu, no se haya configurado la doctrina probable por requerirse un mínimo de tres pronunciamientos, sin embargo, se cuente con pronunciamientos del mismo tribunal o juez frente a casos análogos en los que pretende cambiar de criterio judicial. De esto se derivan las siguientes implicaciones: i), la doctrina probable sigue vigente, de acuerdo a las reglas que la consagran y a su condicionamiento constitucional y ii) se incorporó, de forma tácita, la noción de precedente judicial en el ámbito de la jurisdicción ordinaria, la cual debe cohabitar junto a la de doctrina probable.

La doctrina probable y el precedente judicial son caminos distintos con los que se persiguen fines comunes, esto es, la seguridad jurídica y la garantía del derecho fundamental a la igualdad. Mientras que la primera determina reglas de interpretación de la normativa vigente, el segundo "establece reglas sobre la aplicación de las normas en casos precisos, afecta por lo tanto aquellos casos cuyos hechos se subsuman en la hipótesis y están dirigidos a la parte resolutiva de la decisión" (Corte Constitucional, 2015). 
También se advierte que la jurisprudencia de la Corte Suprema ha incorporado varias de las tesis que han sido desarrolladas por la Corte Constitucional ${ }^{3}$; aunque sus alusiones suelen ser tangenciales y poco profundas. Un ejemplo, puede apreciarse en la sentencia de la Sala de Casación Civil del 5 agosto de 2014, en la que se detuvo a esbozar las diferencias entre: i) jurisprudencia, ii) precedente y iii) doctrina probable. La Corte Suprema enfatizó que el precedente sirve de parámetro para los supuestos enjuiciados, dado que brinda cierto nivel de previsibilidad acerca de la aplicación e interpretación de una disposición legal, por tanto, aceptar tratamientos diferenciados frente a casos iguales implicaría atentar contra la paz y el sosiego social. Planteamiento que debe asumirse sin desconocer que los jueces gozan de autonomía e independencia judicial, ya sea para acoger el precedente o para distanciarse de este a través de su enunciación y la exposición de motivos sólidos (Corte Suprema de Justicia. Sala de Casación Civil, 2014), toda vez que, "aunque los precedentes son vinculantes, no obligan de manera absoluta" (Corte Suprema de Justicia. Sala de Casación Penal, 2013).

La Corte Constitucional ha enunciado tres situaciones en las que la Corte Suprema de Justicia puede separarse de su doctrina probable: i) frente a cambios sociales que hagan necesario un ajuste en la jurisprudencia; ii) cuando encuentre que su jurisprudencia contradice valores, objetivos, principios y derechos en los que se fundamenta el ordenamiento jurídico y iii) cuando se constate un cambio relevante de rango legal o constitucional en el ordenamiento jurídico (Corte Constitucional, 2001).

\section{EL PRECEDENTE JUDICIAL EN LAS DECISIONES DEL CONSEJO DE ESTADO Y SU FUNCIÓN COMO FUENTE PRINCIPAL PARA EL JUEZ CONTENCIOSO ADMINISTRATIVO}

En los anteriores capítulos se ha presentado una breve construcción conceptual que proporciona las bases para comprender las figuras de la jurisprudencia y del precedente judicial en el ámbito contencioso administrativo. A continuación, se abordará el estudio del mismo en dos momentos: el primero, antes de la expedición del Cpaca (Ley 1437 de 2011)y el segundo, después de expedido este código.

\subsection{Antes de la expedición del Cpaca}

Al igual que la Corte Suprema de Justicia, el Consejo de Estado también contó con enunciación constitucional en la Carta de 1886. Sin embargo, su origen constitucional consultivo ("proadministración"), supeditó su ejercicio jurisdiccional a ulteriores desarrollos normativos. Luego, fue suprimido por el Acto Legislativo 10 de 1905.

3 Al respecto véase: Corte Suprema de Justicia (2012). Sala de Casación Penal. Sentencia del 11 de julio. Expediente 38285. M.P. Fernando Alberto Castro Caballero. En esta decisión la Corte emplea la distinción jurisprudencial entre ratio decidendi y obiter dicta. 
No obstante, a través del Acto Legislativo 03 de 1910, desarrollado por la Ley 130 de 1913, se estableció la creación de la denominada jurisdicción de lo contencioso administrativo. Aunque solo sería hasta 1914, con el Acto Legislativo 01, cuando se daría vida a las facultades jurisdiccionales del Consejo de Estado Colombiano (Corte Constitucional, 2001).

Las normas descritas dieron pie al establecimiento de un sistema jurisdiccional dual, compartido entre el Consejo de Estado y la Corte Suprema de Justicia. Para el caso del Consejo de Estado, aunque no logró tener el estatus de unificador de jurisprudencia a nivel de casación, como si lo hacía la Corte Suprema, logró controlar los excesos en las actuaciones de las entidades de los niveles territoriales. En consonancia con esto, su diseño lo posicionó como un órgano jurisdiccional muy especializado para el control de la administración pública en sus distintos niveles, además, ejercía control centralizado a los actos administrativos que fuesen contrarios a la Constitución y las leyes ${ }^{4}$ (Sarmiento, 2011).

En cuanto a su papel como órgano de cierre, se reitera que no se ha llevado a cabo a través de una figura de unificación como la casación, pues ha operado bajo otras formas como son los recursos extraordinarios de revisión y de súplica, los cuales han variado a lo largo de su historia. Entre estos recursos, llama la atención el de súplica, cuya regulación se encontraba en la Ley 11 de 1975 . El artículo $2^{\circ}$ de dicha ley consagraba los fundamentos legales para sostener, en alguna medida, la fuerza vinculante de la jurisprudencia del Consejo de Estado, en el entendido en que, al ser desconocida por las salas o subsecciones, habilitaba la procedencia de un recurso cuya finalidad era la de reorientar las tesis judiciales divergentes, sobre la base de la jurisprudencia contenciosa administrativa imperante en el respectivo momento.

En 1984, el Decreto 01 derogó las normas que regulaban el recurso de súplica; aunque a través de modificaciones ulteriores como las traídas por el Decreto 2304 de 1989 y la Ley 446 de 1998, fueron incorporadas de nuevo al Código de lo Contencioso Administrativo vigente en la época5. Sin embargo, más allá de dichos mecanismos, solo sería con la Ley 1395 de $2010^{6}$, con la que se aludiría a la categoría de precedente en una ley colombiana. En las anteriores leyes se había hecho mención a la jurispru-

4 En la actualidad, el Consejo de Estado no solo es juez de lo contencioso administrativo, también es juez constitucional: ya sea cuando se comporta como juez de tutela o cuando actúa en el ámbito del control abstracto, en los precisos términos del artículo 237 de la Constitución Política de 1991.

5 Con el Cpaca, la regulación en materia del recurso de súplica cuenta hoy con una naturaleza diferente, pierde la función unificadora y orientadora de otrora. En la actualidad existen otras figuras como las sentencias de unificación jurisprudencial y la extensión de jurisprudencia, que cumplirían (en teoría) con los mismos propósitos.

6 En los artículos 29, 114 y 115 se pueden apreciar las alusiones explícitas al precedente judicial. 
dencia, a la doctrina legal, a la doctrina probable, pero no al precedente, su alusión solo había sido de carácter jurisprudencial y doctrinario.

En lo que interesa al ámbito contencioso administrativo, el artículo 114 de la Ley 1395 de 2010 trajo al plano legal la subregla que la Corte Constitucional había establecido en la Sentencia T-116 de 2004, según la cual, su precedente judicial y el de los demás órganos -en su respectivo ámbito competencial-, se entendía como obligatorio para las autoridades administrativas. Teniendo en cuenta que los jueces poseen prerrogativas como la autonomía e independencia funcional, que les permiten (bajo determinadas circunstancias) apartarse del precedente judicial, lo cual no sucede cuando se trata de autoridades administrativas (Corte Constitucional, 2006).

Artículo legal que daba cuenta de un desarrollo jurisprudencial previo en materia de precedentes, excepto en cuanto a que fijó un número mínimo de cinco o más casos análogos que debían ser proferidos para configurar precedente. Estipulación legislativa que parecía problemática por la alta exigencia numérica. No obstante, sin desconocer la teleología de descongestión judicial que inspiró al mencionado artículo, la Corte Constitucional (2011a), a través de la Sentencia C-539, declaró la exequibilidad de algunas de sus expresiones. El argumento central de la decisión fue el mismo que el de la Sentencia T-116 de 2004, en términos de resaltar la obligatoriedad del precedente judicial en casos análogos o similares para las autoridades administrativas, quienes no gozan de la autonomía e independencia judicial.

Sumado a lo anterior, la Corte condicionó el artículo, en el sentido de incluir también la interpretación vinculante que realiza la Corte Constitucional, ya que el legislador solo lo había establecido para la jurisdicción administrativa y la ordinaria (Corte Constitucional, 2011a). Aunque esta figura tendría una corta vida jurídica, puesto que a través de la Ley 1437 de 2011 (Cpaca), el artículo 114 de la Ley 1395 de 2010 sería derogado de forma expresa.

\subsection{Después de la expedición del Cpaca}

La expedición del Cpaca trajo consigo varios cambios en el derecho administrativo colombiano, algunos de ellos referidos al recurso extraordinario de unificación de jurisprudencia (artículos 256 y ss.); la extensión de jurisprudencia a terceros (artículo 102); el procedimiento judicial para la extensión de jurisprudencia (artículo 269) y las sentencias de unificación jurisprudencial (artículos 10, 270 y 271). Temas de gran importancia cuyo tratamiento rebasaría los alcances de este texto, razón por la cual, este acápite solo se ocupa de las sentencias de unificación jurisprudencial del Consejo de Estado, como temática de necesario desarrollo frente al objetivo planteado en este artículo. 
Para empezar, se debe precisar que el término precedente no se consagra de forma explícita en el Cpaca, aunque sí se establece una regulación muy completa e interesante sobre las sentencias de unificación jurisprudencial. En el artículo 10 se regula el deber de aplicación uniforme de las normas y la jurisprudencia, para lo cual dispone que:

Al resolver los asuntos de su competencia, las autoridades aplicarán las disposiciones constitucionales, legales y reglamentarias de manera uniforme a situaciones que tengan los mismos supuestos fácticos y jurídicos. Con este propósito, al adoptar las decisiones de su competencia, deberán tener en cuenta las sentencias de unificación jurisprudencial del Consejo de Estado en las que se interpreten y apliquen dichas normas.

Frente al artículo precitado es importante resaltar que no se trata de cualquier tipo de decisión judicial del alto tribunal, solo está referido a un tipo cualificado de las mismas ${ }^{7}$, es decir, aquellas que son definidas según el artículo 270 del Cpaca en los siguientes términos:

Se tendrán como sentencias de unificación jurisprudencial las que profiera o haya proferido el Consejo de Estado por importancia jurídica o trascendencia económica o social o por necesidad de unificar o sentar jurisprudencia; las proferidas al decidir los recursos extraordinarios y las relativas al mecanismo eventual de revisión previsto en el artículo 36A de la Ley 270 de 1996, adicionado por el artículo 11 de la Ley 1285 de 2009.

Por su parte, el artículo 271 del Cpaca se encarga de enunciar los eventos frente a los que es procedente la expedición de sentencias de unificación jurisprudencial por razones de importancia jurídica, trascendencia económica o social, o por necesidad de sentar jurisprudencia. Indicó, además, que en estos casos corresponderá a la Sala Plena de lo Contencioso Administrativo del Consejo de Estado, cuando los asuntos provengan de las secciones. Mientras que, de otro lado, corresponderá a las secciones tratándose de asuntos originados en la subsecciones, o que provengan de los tribunales de distrito judicial. Ahora bien, teniendo en cuenta que el Consejo de Estado, por lo general, actúa como juez de segunda instancia, surgen los siguientes interrogantes: ¿Solo se configurará el precedente judicial ante sentencias de unificación jurisprudencial? ¿En qué eventos podría el Consejo de Estado apartarse de sus decisiones?

Para dar respuesta a estos interrogantes es necesario volver a lo dicho por la Corte Constitucional cuando se pronunció sobre la constitucionalidad de la doctrina probable. En aquella ocasión también lo hizo frente al alto tribunal de lo contencioso

$7 \quad$ Debe tenerse en cuenta que se trata de decisiones judiciales en instancia de unificación, emitidas por el Consejo de Estado; aunque también habría que considerar las sentencias de unificación de la Corte Constitucional, incluso, estas últimas se aplicarán de manera preferente, siempre y cuando interpreten normas de rango constitucional que sean aplicables a asuntos de competencia del Consejo de Estado, sin que por ello se desconozca, como ya se ha planteado, el rasgo erga omnes de las sentencias C (Corte Constitucional, 2011b). 
administrativo. Para la época en que surgió la regulación sobre la doctrina probable, el Consejo de Estado no tenía funciones jurisdiccionales; sin embargo, tanto esta como la autonomía judicial son atributos propios de todos los órganos judiciales, sin perjuicio de sus rasgos particulares. En consecuencia, esta competencia es "predicable de los jueces que integran la administración de justicia, tanto los que corresponden a la denominada jurisdicción ordinaria, como a los que pertenecen a la justicia administrativa y constitucional" (Corte Constitucional, 2001).

En síntesis, si se aplican las mismas reglas jurisprudenciales que se han esbozado en este artículo para efectos de diferenciar la ratio decidendi de los obiter dicta de cualquier decisión del Consejo de Estado y se interpretan de forma sistemática con el Cpaca, se tendría que asumir que es suficiente con la existencia de una decisión de este máximo tribunal para contar con un precedente judicial. De hecho, antes de la promulgación del Cpaca, los grandes avances en materia contenciosa administrativa se consolidaron bajo el comportamiento de precedentes judiciales, de igual manera, los cambios que se ocasionaron frente a los mismos.

En cuanto a su vinculatoriedad, por expreso mandato del Cpaca, las sentencias de unificación jurisprudencial gozan de un reforzamiento legal indiscutible. En cambio, frente a las demás decisiones que profiera el Consejo de Estado y sean distintas a las de unificación, sería necesario recurrir a los supuestos existentes en materia de precedente judicial (ratio decidendi) para exigir su aplicación como fuente principal frente a casos análogos y similares. Claro está, debe tenerse en cuenta que en Colombia el precedente es, en términos de Igartúa (2006), 'prejuzgante'; esto es, atendiendo a la autonomía e independencia judicial, el juez cuenta con la posibilidad de separarse del mismo en presencia de mejores razones, siempre mediadas por rigurosos ejercicios argumentativos que cumplan con las cargas de la argumentación, motivación y transparencia en la justificación del cambio de postura judicial.

\section{CONCLUSIONES}

Para el juez colombiano existe un esquema de fuentes del derecho de consagración constitucional, que las separa en fuentes principales y auxiliares. Dicho esquema ha requerido la intervención de la Corte Constitucional, que a través de sus distintas sentencias ha delimitado su interpretación. El contexto de estas intervenciones se ha propiciado a partir de dificultades de tipo práctico y conceptual, originadas en torno a las instituciones del precedente judicial y la jurisprudencia, en cuanto a la falta de claridad sobre su fuerza vinculante y, por tanto, su estatus de fuente principal o auxiliar.

Estas intervenciones han sido dinámicas, lo que ha hecho del esquema de fuentes un escenario cambiante con relación a las interpretaciones que sobre él han recaído, 
en especial, durante el periodo posterior a la expedición de la Constitución Política de 1991. Entre las causas por las que el esquema de fuentes ha sido intervenido en este punto, se encuentran razones: i) de tipo cultural y ii) de tipo conceptual, al tratar, por lo general, como sinónimos al precedente judicial y a la jurisprudencia.

En Colombia el precedente judicial no cuenta con una consagración constitucional explícita, en consecuencia, este escenario ha sido más propicio para trabajar-como lo fue durante mucho tiempo- con la idea de una jurisprudencia como fuente auxiliar y no con la idea de un precedente como fuente principal. Sin embargo, más allá de su falta de enunciación expresa, hoy es dominante la tesis que acepta la fuerza vinculante del precedente como fuente principal, pero como precedente prejuzgante. Este último rasgo en atención a la autonomía e independencia judicial como prerrogativas que el constituyente estableció para la garantía de los derechos por parte de las autoridades jurisdiccionales.

Aunque cada una de las distintas áreas jurisdicciones ha tenido su propia historia y desarrollo en torno al precedente judicial, en la práctica han compartido la mayoría de sus dificultades. Lo anterior ha hecho que, tanto la jurisdicción constitucional, 'ordinaria' y contenciosa administrativa, compartan los mismos fundamentos teóricos y prácticos que, a través de figuras como la ratio decidendi, han dotado de vinculatoriedad algunos elementos de la decisión judicial, cuyos efectos, en principio, solo eran interpartes; sin embargo, luego fueron modulados y extendidos (caso de la Corte Constitucional y sus decisiones, como ejemplo por excelencia).

Para el caso de la jurisdicción contenciosa administrativa, es necesario tomar como fundamentos comunes los desarrollados por la Corte Constitucional frente al precedente judicial, puesto que gran parte de estos han sido incorporados en las decisiones del Consejo de Estado. Sumado a ello, existe una diferencia sustancial entre esta jurisdicción y las demás, la cual estriba en el reforzamiento legal con el que cuenta en la actualidad el precedente a través de figuras como la extensión de jurisprudencia, el recurso extraordinario de unificación y las sentencias de unificación jurisprudencial, consagradas en el Cpaca.

Las sentencias de unificación jurisprudencial son sentencias cualificadas que poseen fuerza vinculante explícita de rango legal. Sin embargo, no solo ellas configuran precedente judicial, de acuerdo con un entendimiento sistemático del ordenamiento y la teoría de la ratio decidendi, sería posible sostener que en cualquier otra sentencia del Consejo de Estado se pueden extraer subreglas judiciales exigibles como precedentes sobre otros casos que sean análogos o similares, atendiendo a sus aspectos fácticos y normativos. Tal exigibilidad se soportaría en la protección al derecho fundamental a la igualdad, la buena fe, la confianza legítima de los ciudadanos ante la administración 
de justicia y la unidad y sistematicidad del ordenamiento jurídico. Situación que ya ocurría en la práctica, incluso antes de la expedición del Cpaca, prueba de ello son los abundantes desarrollos jurisprudenciales del Consejo de Estado en las diferentes materias de su competencia.

\section{REFERENCIAS}

Aguiló, J. (2015). Fuentes del derecho. En J. Fabra (Ed.), Enciclopedia de filosofía y teoría del derecho (pp. 1019-1066). Ciudad de México: Universidad Nacional Autónoma de México.

Bernal, C. (2008). El precedente judicial en Colombia. Revista Derecho del Estado, (21), 81-94.

Cárdenas Gracia, J. (2009). Introducción al estudio del derecho. Ciudad de México: Universidad Nacional Autónoma de México-Nostra Ediciones.

Colombia. Congreso de la República. (1896). Ley 169 del 31 de diciembre, sobre reformas judiciales. Diario Oficial 10.235 del 4 de noviembre de 1896.

Colombia. Congreso de la República. (1905). Acto legislativo 10 del 27 de abril reformatorio de la Constitución por el cual se deroga el Título XIII de la misma. Diario Oficial 12.346 de 10 de mayo 1905.

Colombia. Congreso de la República. (1910). Acto legislativo 03 del 31 de octubre reformatorio de la Constitución Nacional. Diario Oficial 14.131 del 31 de octubre 1910.

Colombia. Congreso de la República. (1914). Acto legislativo 03 del 10 de septiembre por el cual se restablece el Consejo de Estado. Diario Oficial 14.131 del 31 de octubre.

Colombia. Congreso de la República. (1975). Ley 11 del 13 de enero, por la cual se aclaran y adicionan los artículos 22 y 24 del Decreto-ley 528 de 1964 y el artículo $4^{\circ}$ de la Ley 50 de 1967 y se modifica el 25 de la Ley 167 de 1941, sobre funcionamiento del Consejo de Estado. Diario Oficial 34.245 del 29 de enero.

Colombia. Congreso de la República. (1996). Ley 270 del 15 de marzo. Ley Estatutaria de la Administración de Justicia. Diario Oficial 42.745 del 15 de marzo.

Colombia. Congreso de la República. (2010). Ley 1395 de 12 de julio, por la cual se adoptan medidas en materia de descongestión judicial. Diario Oficial 47.768 del 12 de julio.

Colombia. Congreso de la República. (2011). Ley 1437 de 18 de enero por la cual se expide el Código de Procedimiento Administrativo y de lo Contencioso Administrativo. Diario Oficial 47.956 del 18 de enero de 2011.

Colombia. Congreso de la República. (2012). Ley 1564 de julio 12 por medio de la cual se expide el Código General del Proceso y se dictan otras disposiciones. Diario Oficial 48.489 de julio 12 de 2012.

Colombia. Presidencia de la República. (1984). Decreto 01 de 2 de enero, por el cual se reforma el Código Contencioso Administrativo. Diario Oficial 36.439 del 10 de enero. 
Colombia. Presidencia de la República. (1991). Decreto 2067 del 4 de septiembre, por el cual se dicta el régimen procedimental de los juicios y actuaciones que deban surtirse ante la Corte Constitucional. Diario Oficial 40.012 del 4 de septiembre de 1991.

Constitución Política de Colombia. (1991). Recuperado de http://www.secretariasenado.gov.co/senado/ basedoc/constitucion_politica_1991.html

Corte Constitucional de Colombia. (1993). Sentencia C-131 de abril 1. M.P. Martínez Caballero, A.

Corte Constitucional de Colombia. (1995a). Sentencia T-260 de junio 20. M.P. Hernández, J. G.

Corte Constitucional de Colombia. (1995b). Sentencia T-175 de abril 24. M.P. Cifuentes, E.

Corte Constitucional de Colombia. (1996). Sentencia C-037 de febrero 5. M.P. Naranjo Mesa, V.

Corte Constitucional de Colombia. (1999). Sentencia SU-047 de enero 29. M.P. Alejandro Martínez, A. y Gaviria, C.

Corte Constitucional de Colombia. (2001). Sentencia C-836 de agosto 9. M.P. Escobar Gil, R.

Corte Constitucional de Colombia. (2006a). Auto 223 de agosto 16. M.P. Córdoba Triviño, J.

Corte Constitucional de Colombia. (2006b). Sentencia T-158 de enero 29. M.P. Sierra Porto, H.

Corte Constitucional de Colombia. (2006). Sentencia T-116 de febrero 12. M.P. Montealegre, E.

Corte Constitucional de Colombia. (2011). Sentencia C-539 de julio 6. M.P. Vargas, L.

Corte Constitucional de Colombia. (2011b, 24 de agosto). Sentencia C-634 de agosto 24. M.P. Vargas, L.

Corte Constitucional de Colombia. (2015). Sentencia C-621 de septiembre 30. M.P. Pretelt Chaljud, J.

Corte Suprema de Justicia. Sala de Casación Penal. (2012). Sentencia del 11 de julio. Expediente 38285. M.P. Castro Caballero, F.

Corte Suprema de Justicia. Sala de Casación Penal. (2013). Sentencia del 20 de noviembre. Expediente 38285. M.P. Barceló Camacho, J.

Corte Suprema de Justicia. Sala de Casación Civil. (2014). Sentencia del 5 de agosto. Expediente 10304. M.P. Tolosa Villabona, L.

Díez, S. (2008). El precedente administrativo. Fundamentos y eficacia vinculante. España: Marcial Pons.

García, L. (2004). El sistema Jurídico del common law. Preámbulo para una investigación en derecho comparado. Centro de Investigaciones Sociojurídicas, 1(2), 71-92.

Igartúa, J. (2006). La fuerza vinculante del precedente judicial. Isegoría, (35), 193-205.

Sarmiento, J. (2011). El recurso extraordinario de unificación jurisprudencial chacia la instauración de un juez de casación en lo contencioso-administrativo? Vniversitas, (123), 247-282.

Taruffo, M. (2007). Precedente y jurisprudencia. Precedente, (2), 87-101. 